\title{
The impact of preoperative epidural injections on postoperative infection in lumbar fusion surgery
}

\author{
Anuj Singla, MD,, 1 Scott Yang, MD, ${ }^{2}$ Brian C. Werner, MD, ${ }^{1}$ Jourdan M. Cancienne, MD, ${ }^{1}$ \\ Ali Nourbakhsh, MD, ${ }^{1}$ Adam L. Shimer, MD, ${ }^{1}$ Hamid Hassanzadeh, MD, ${ }^{1}$ and Francis H. Shen, MD'1 \\ ${ }^{1}$ Department of Orthopaedic Surgery, University of Virginia Health System, Charlottesville, Virginia; and ${ }^{2}$ Children's Orthopaedic \\ Center, Children's Hospital Los Angeles, California
}

\begin{abstract}
OBJECTIVE Lumbar epidural steroid injections (LESIs) are performed for both diagnostic and therapeutic purposes for a variety of indications, including low-back pain, the leading cause of disability and expense due to work-related conditions in the US. The steroid agent used in epidural injections is reported to relieve nerve root inflammation, local ischemia, and resultant pain, but the injection may also have an adverse impact on spinal surgery performed thereafter. In particular, the possibility that preoperative epidural injections may increase the risk of surgical site infection after lumbar spinal fusion has been reported but has not been studied in detail. The goal of the present study was to use a large national insurance database to analyze the association of preoperative LESIs with surgical site infection after lumbar spinal fusion.
\end{abstract}

METHODS A nationwide insurance database of patient records was used for this retrospective analysis. Current Procedural Terminology codes were used to query the database for patients who had undergone LESI and 1- or 2-level lumbar posterior spinal fusion procedures. The rate of postoperative infection after 1- or 2-level posterior spinal fusion was analyzed. These study patients were then divided into 3 separate cohorts: 1) lumbar spinal fusion performed within 1 month after LESI, 2) fusion performed between 1 and 3 months after LESI, and 3) fusion performed between 3 and 6 months after LESI. The study patients were compared with a control cohort of patients who underwent lumbar fusion without previous LESI.

RESULTS The overall 3-month infection rate after lumbar spinal fusion procedure was $1.6 \%$ (1411 of 88,540 patients). The infection risk increased in patients who received LESI within 1 month (OR 2.6, p < 0.0001) or 1-3 months (OR 1.4, $p=0.0002)$ prior to surgery compared with controls. The infection risk was not significantly different from controls in patients who underwent lumbar fusion more than 3 months after LESI.

CONCLUSIONS Lumbar spinal fusion performed within 3 months after LESI may be associated with an increased rate of postoperative infection. This association was not found when lumbar fusion was performed more than 3 months after LESI.

https://thejns.org/doi/abs/10.3171/2016.9.SPINE16484

KEY WORDS epidural injection; lumbar fusion; infection; postoperative complications; spine surgery

$\mathrm{L}$ OW-BACK pain, along with its related neurological symptoms, represents one of the most significant health care burdens. Low-back pain is the leading cause of disability and expense due to work-related conditions in the US. Forty percent of workers' compensation expenses are reported to be related to claims involving the low back. ${ }^{18}$ The number of patients with spinal problems has grown exponentially in the recent past, and back pain and related radicular pain are the second most common symptom-related cause for medical office visits in the US.., 34
Lumbar epidural steroid injections (LESIs) are the most common nonsurgical interventions performed for the management of lumbar stenosis or radiculopathy; ${ }^{26}$ they are performed for both diagnostic and therapeutic purposes. Rates of transforaminal LESIs have increased $665 \%$ since 2000, with more than 2.2 million procedures performed each year in the Medicare population. ${ }^{21}$ Nerve root inflammation, local ischemia, and resultant pain are reported to be reduced by the potent antiinflammatory effects of glucocorticoids. ${ }^{1,13,22,34}$ These injections provide an excellent nonsurgical option; however, their short-term and long-

ABBREVIATIONS CPT = Current Procedural Terminology; ICD-9 = International Classification of Diseases, 9th Revision; LESI = lumbar epidural steroid injection. SUBMITTED May 20, 2016. ACCEPTED September 23, 2016.

INCLUDE WHEN CITING Published online March 14, 2017; DOI: 10.3171/2016.9.SPINE16484. 
TABLE 1. Comorbidity and demographics for matched cohorts

\begin{tabular}{|c|c|c|c|c|c|c|c|}
\hline \multirow[b]{2}{*}{ Variable } & \multicolumn{3}{|c|}{ Injection Group } & \multirow{2}{*}{$\begin{array}{l}\text { Control } \\
\text { Group }\end{array}$} & \multicolumn{3}{|c|}{ p Value* } \\
\hline & 0-1 Mo & 1-3 Mos & 3-6 Mos & & 1-3 Mos & 3-6 Mos & Control \\
\hline No. of individuals & 1699 & 5491 & 10,493 & 70,857 & & & \\
\hline \multicolumn{8}{|l|}{ Age (yrs), \% } \\
\hline $65-69$ & 32.9 & 32.4 & 32.8 & 33.1 & 0.688 & 0.954 & 0.880 \\
\hline $70-74$ & 26.5 & 26.7 & 26.4 & 26.7 & 0.886 & 0.913 & 0.856 \\
\hline $75-79$ & 22.3 & 22.3 & 22.8 & 22.2 & 0.976 & 0.649 & 0.892 \\
\hline $80-84$ & 12.5 & 12.8 & 12.2 & 12.3 & 0.755 & 0.753 & 0.858 \\
\hline$>85$ & 5.8 & 5.9 & 5.8 & 5.7 & 0.888 & 0.957 & 0.877 \\
\hline Female sex, \% & 58.9 & 58.9 & 58.9 & 58.9 & 0.999 & 0.999 & 1.00 \\
\hline Diabetes mellitus, \% & 35.7 & 35.7 & 35.7 & 35.7 & 0.992 & 0.999 & 0.999 \\
\hline Smoking history, \% & 36.0 & 35.9 & 36.0 & 36.0 & 0.992 & 0.997 & 1.00 \\
\hline Obesity, \% & 25.1 & 25.1 & 25.1 & 25.1 & 0.990 & 1.00 & 1.00 \\
\hline
\end{tabular}

The time intervals represent the number of months between the LESI and lumbar spinal fusion.

* Compared with the index group (0-1 month).

term efficacy continue to be matters of debate. There are conflicting data in the literature regarding the long-term efficacy of LESIs for lumbar radiculopathy.,2,20,28,29

Although epidural injections are generally considered to be relatively safe, reported risks include vasovagal episodes, procedure interruption because of intravascular flow, pain exacerbation, injection site soreness, and headache. ${ }^{11,25}$ In addition to the adverse effects and the questionable long-term efficacy of epidural injections, their use may compromise subsequent surgical procedures and their outcomes. Recent studies have suggested a higher incidence of postoperative infection in patients who undergo lumbar spinal surgeries after preoperatively administered epidural injections..$^{34,36}$ The goal of the present study was to use a large national database to analyze the association between preoperative LESIs administered at various time intervals before lumbar spinal fusion and the incidence of surgical site infection.

\section{Methods}

The PearlDiver patient record database (PearlDiver Inc.), an insurance-based nationwide database, was used for this retrospective analysis. The data are de-identified and anonymous, and thus their use did not require institutional review board approval. The data for the present study were derived from a Medicare database within the overall PearlDiver database and were limited to patients older than 65 years. The Medicare database has more than 100 million patient records from 2005 to 2012. The database contains procedural volumes and demographic information for patients with Current Procedural Terminology (CPT) codes or International Classification of Diseases, 9th Revision (ICD-9) diagnoses and procedures.

The analysis was designed to evaluate the surgical site infection rate after 1- or 2-level posterior lumbar spinal fusion and the association with preoperative epidural injections. The database was queried for 1- or 2-level lumbar posterior spinal fusion procedures using CPT codes 22612, 22614, 22633, and 22630. Revision lumbar procedures, identified by CPT codes 22830, 63042, and 63044, were excluded. Data for patients who underwent LESI were queried using CPT code 64483 or 62311.

Patients who underwent 1- or 2-level lumbar spinal fusions after LESI were then identified using Boolean coding within the database and were divided into 3 separate cohorts: 1) lumbar fusion performed within 1 month after LESI, 2) lumbar fusion performed between 1 and 3 months after LESI, and 3) lumbar fusion performed between 3 and 6 months after LESI. A control group was created for comparison purposes, which included all patients meeting the above procedural criteria without a previous documented LESI. The control group was then matched to the 3 study cohorts by using the maximum number of available patients with a similar distribution of several key variables: age, sex, obesity, smoking history, and diabetes mellitus.

Postoperative infection within 90 days of the index lumbar spinal fusion was assessed using the following ICD-9 and CPT codes: ICD-9 codes 998.5, 998.51, 998.59, and 996.67; and CPT codes 20005 and 22015.

Statistical comparisons of cohort demographics and postoperative infection rates between the study and control groups were performed using Pearson chi-square analysis. Odds ratios and their $95 \%$ confidence intervals were calculated. For all statistical comparisons, $\mathrm{p}<0.05$ was considered significant. SPSS software (version 22 for Macintosh, IBM) was used for all statistical calculations.

\section{Results}

Four mutually independent cohorts were found, a total of 88,540 patients. The 3 treatment groups included a total of 17,683 patients, 1699 patients treated with LESI $0-1$ month prior to lumbar fusion, 5491 patients treated with LESI 1-3 months prior to lumbar fusion, and 10,493 patients treated with LESI 3-6 months prior to lumbar fusion. The control group included 70,857 patients. A comparison of demographic characteristics and comorbidities revealed similar distributions of age, sex, diabetes mellitus, smoking, and obesity in the control and treatment groups (Table 1).

The incidence of postoperative infection after surgery 
within 90 days postoperatively for each cohort is presented in Table 2. The overall 3-month infection rate for lumbar spinal fusion was $1.6 \%$ (1411 of 88,540). The infection rate was 3.9\% (66 of 1699) in patients receiving LESI within 1 month, 2.2\% (120 of 5491) in patients receiving LESI within 1-3 months, and $1.3 \%$ (136 of 10,493) in patients receiving LESI 3-6 months before fusion. The infection rate was noted to be significantly higher in patients receiving LESI within 1 month (OR 2.6, $\mathrm{p}<0.0001)$ and $1-3$ months (OR $1.4, p=0.0002)$ prior to surgery compared with controls. In patients who received LESI more than 3 months before fusion, the infection risk was not significantly higher than that for the control group (OR 0.8, $\mathrm{p}=0.06$ ).

\section{Discussion}

Epidural injections are generally considered a first-line treatment prior to a more extensive spinal surgery, primarily because of the minimal risks involved. However, in addition to the debate regarding efficacy, these injections have their own set of potential adverse effects. In a retrospective analysis, Plastaras et al. ${ }^{25}$ documented adverse events after 2025 transforaminal epidural injections in 1295 consecutive patients, with overall incidences of $9.2 \%$ (182 injections) and 20.0\% (305 injections). Early and delayed complications included vasovagal reaction, interrupted procedure from intravascular flow, pain exacerbation, injection site soreness, headache, facial flushing/ sweating, and insomnia. ${ }^{25}$ Other uncommon but significant adverse effects reported in the literature include adhesive arachnoiditis, perineal pruritus, insomnia, hiccups, flushing, increased radicular pain, epidural abscess, cervical myelomeningitis, and infection. ${ }^{9-12,14,15,19,23,25,27,30,35}$

Steroid injection is a known risk factor for local and/ or distant infection. The increased risk of infection can be attributed to exogenous material introduction through the skin into the spinal epidural space, skin flora, contaminated injection material, ${ }^{34}$ and immunosuppressive effects of steroid agents. Contaminated sources of epidural steroid injections have led to cases of fulminant and potentially fatal infections, including fungal meningitis that resulted in 12 deaths. ${ }^{5}$ Development of injection site infection and/or distant infection is not uncommon after epidural injections. Multiple case reports have documented local and distant infections and abscess formation after injection, ${ }^{6,12,14-17,25,27,35}$ including extensive cervico-thoraco-lumbo-sacral spinal subdural abscesses. . $^{17,24}$

The increased risk of surgical site infection after preoperative and intraoperative local steroid injection has been well established in the literature for various orthopedic procedures. ${ }^{3,431-33}$ However, there are limited existing data that shed light on the association between preoperative LESI and postoperative infection after lumbar spine surgery. Results of a recent database analysis suggested an increased rate of postoperative surgical site infection after lumbar decompression in patients with a history of epidural injections. ${ }^{34}$ In this study, analysis of the complication rate in single-level lumbar decompression within 12 months after epidural injection revealed a higher incidence of infection if the injection was administered within 3 months before the decompression. ${ }^{34}$ The infection rates
TABLE 2. Postoperative infection risk in the control group versus the injection group

\begin{tabular}{lcccc}
\hline & Control & \multicolumn{3}{c}{ Injection Group } \\
\cline { 3 - 5 } Variable & Group & 0-1 Mo & 1-3 Mos & 3-6 Mos \\
\hline $\begin{array}{c}\text { No. of indi- } \\
\text { viduals }\end{array}$ & 70,857 & 1699 & 5491 & 10,493 \\
\hline $\begin{array}{c}\text { No. of postop } \\
\text { infections } \\
(\%)\end{array}$ & $1089(1.5)$ & $66(3.9)$ & $120(2.2)$ & $136(1.3)$ \\
\hline OR $(95 \% \mathrm{Cl})$ & & & & \\
\hline p value & $2.6(2.0-3.3)$ & $1.4(1.2-1.7)$ & $0.8(0.7-1.0)$ \\
\hline
\end{tabular}

Boldface type indicates statistical significance.

we documented in the current study follow a similar trend, with higher rates of infection after injections performed closer to the time of surgery.

Zusman et al. ${ }^{36}$ suggested the possibility of an increased risk of postoperative infection after lumbar fusion in patients who received preoperative epidural injections. Their study compared the surgical outcomes of lumbar fusion in patients with a history of epidural injections (117 patients) with those in patients who did not receive epidural injections (163 patients). The surgical outcomes and overall complication rates were reported to be similar for both groups, except that there was a 7.4-fold higher risk of surgical site infection in patients who received injections $5.1 \%$ for patients who received epidural injections vs $0.6 \%$ for those who did not). ${ }^{36}$ Our study also suggests higher infection rates of 3.9\% (66 of 1699) in patients receiving LESI within 1 month and 2.2\% (120 of 5491) in patients receiving LESI within 1-3 months of surgery. The infection rates in our study are slightly lower than those reported by Zusman et al., but our results suggest a similar trend of increased risk of infection after injections in a much larger study population.

The timing of injection prior to surgery can also be an important factor, as suggested by the current study finding that the risk of surgical site infection is higher if the preoperative injection is administered closer to the time of surgery. The incidence of postoperative infection was not higher for patients receiving LESI than for controls if the epidural injection was administered more than 3 months prior to surgery. It is possible that the immunosuppressive effect of a local steroid agent wears off after a specific time and thereafter does not contribute to any higher risk of infection. A similar increased infection risk has been reported after local preoperative injections in knee replacement ${ }^{4}$ and ankle, ${ }^{33}$ shoulder, ${ }^{32}$ and hip ${ }^{31}$ surgery if the injection was administered within 3 months prior to the surgery.

Although in our study the risk of infection was noted to be higher if the epidural injection was administered within 3 months prior to fusion, this finding may also be attributable to comparatively severe symptoms and stenosis in patients who do not experience any significant relief from the injection and subsequently opt for a surgical procedure. Severe stenosis itself can be a risk factor for longer operative times and hence a higher rate of infection.

There are a number of limitations inherent to the database used for this study, the first of which is the inability 
to perform a multivariate analysis of comorbid conditions. To overcome this limitation, we included a matched control cohort with age distribution and rates of smoking, obesity, and diabetes mellitus similar to those of the study cohorts. Matching of the study and control groups for these common independent risk factors for infection helps to minimize the influence of these potential confounding variables. Furthermore, in this study we attempted to provide homogeneous study groups by limiting the evaluation to Medicare patients older than 65 years undergoing 1- or 2-level fusion surgery.

This study also shares the inherent limitation of any large database study of relying on the reported CPT and ICD-9 codes, the accuracy of which cannot be verified. Because our information was obtained from a nationwide insurance-based database, we cannot rule out bias in reporting, patient selection, or surgical indication. Several clinical patient data details, including the number of previous LESIs, total steroid dosage, level of injections (single vs multilevel), adjunctive use of systemic steroids, complexity of the surgical procedure, use and type of bone graft, and instrumentation used for fusion, are unknown due to database limitations. Patients who underwent prior lumbar fusion procedures were excluded from the current study to provide homogeneity. However, the potential impact of a prior nonfusion lumbar procedure, including decompression, cannot be ruled out.

To our knowledge this is the largest study so far to suggest a higher surgical complication rate in patients undergoing lumbar fusion after epidural injections, and our results make a case for further well-designed studies to evaluate this association in more detail. We recommend including the current findings in discussions with patients regarding surgical risk factors, particularly if the surgery is planned soon after injections.

\section{Conclusions}

This study demonstrates the potential for an increased risk of postoperative infection in patients who undergo lumbar fusion surgery within 3 months of LESI treatment. Although the overall infection rate remains low despite the use of preoperative LESIs, increasing the time interval to more than 3 months from injections to surgery may help to reduce this increased risk.

\section{References}

1. Abram SE: Treatment of lumbosacral radiculopathy with epidural steroids. Anesthesiology 91:1937-1941, 1999

2. Briggs VG, Li W, Kaplan MS, Eskander MS, Franklin PD: Injection treatment and back pain associated with degenerative lumbar spinal stenosis in older adults. Pain Physician 13:E347-E355, 2010

3. Cancienne JM, Gwathmey FW, Werner BC: Intraoperative corticosteroid injection at the time of knee arthroscopy is associated with increased postoperative infection rates in a large Medicare population. Arthroscopy 32:90-95, 2016

4. Cancienne JM, Werner BC, Luetkemeyer LM, Browne JA: Does timing of previous intra-articular steroid injection affect the post-operative rate of infection in total knee arthroplasty? J Arthroplasty 30:1879-1882, 2015

5. Centers for Disease Control and Prevention (CDC): Multi- state outbreak of fungal infection associated with injection of methylprednisolone acetate solution from a single compounding pharmacy-United States, 2012. MMWR Morb Mortal Wkly Rep 61:839-842, 2012

6. Chan ST, Leung S: Spinal epidural abscess following steroid injection for sciatica. Case report. Spine (Phila Pa 1976) 14:106-108, 1989

7. Cosgrove JL, Bertolet M, Chase SL, Cosgrove GK: Epidural steroid injections in the treatment of lumbar spinal stenosis efficacy and predictability of successful response. Am J Phys Med Rehabil 90:1050-1055, 2011

8. Deyo RA, Mirza SK, Martin BI, Kreuter W, Goodman DC, Jarvik JG: Trends, major medical complications, and charges associated with surgery for lumbar spinal stenosis in older adults. JAMA 303:1259-1265, 2010

9. El Abd O, Amadera J, Pimentel DC, Gomba L: Immediate and acute adverse effects following transforaminal epidural steroid injections with dexamethasone. Pain Physician 18:277-286, 2015

10. El Abd O, Pimentel DC, Amadera JE: Generalized pruritus as an unusual side effect after epidural injection with dexamethasone. PM R 7:206-209, 2015

11. Epstein NE: The risks of epidural and transforaminal steroid injections in the spine: commentary and a comprehensive review of the literature. Surg Neurol Int 4 (2 Suppl 2):S74S93, 2013

12. Götz F, Lanfermann H, Becker H: [Cervical epidural abscess following lumbar epidural steroid injections.] Klin Neuroradiol 19:220-226, 2009 (Ger)

13. Harrast MA: Epidural steroid injections for lumbar spinal stenosis. Curr Rev Musculoskelet Med 1:32-38, 2008

14. Hoelzer BC, Weingarten TN, Hooten WM, Wright RS, Wilson WR, Wilson PR: Paraspinal abscess complicated by endocarditis following a facet joint injection. Eur J Pain 12:261-265, 2008

15. Hooten WM, Mizerak A, Carns PE, Huntoon MA: Discitis after lumbar epidural corticosteroid injection: a case report and analysis of the case report literature. Pain Med 7:46-51, 2006

16. Knight JW, Cordingley JJ, Palazzo MG: Epidural abscess following epidural steroid and local anaesthetic injection. Anaesthesia 52:576-578, 1997

17. Kraeutler MJ, Bozzay JD, Walker MP, John K: Spinal subdural abscess following epidural steroid injection. J Neurosurg Spine 22:90-93, 2015

18. Langworthy JR: Evaluation of impairment related to low back pain. J Med Syst 17:253-256, 1993

19. Lee Y, Kim JS, Kim JY: Cervical meningomyelitis after lumbar epidural steroid injection. Ann Rehabil Med 39:504507, 2015

20. Manchikanti L, Cash KA, McManus CD, Pampati V, Abdi S: Preliminary results of a randomized, equivalence trial of fluoroscopic caudal epidural injections in managing chronic low back pain: Part 4-Spinal stenosis. Pain Physician 11:833-848, 2008

21. Manchikanti L, Pampati V, Falco FJ, Hirsch JA: Assessment of the growth of epidural injections in the Medicare population from 2000 to 2011. Pain Physician 16:E349-E364, 2013

22. McLain RF, Kapural L, Mekhail NA: Epidural steroids for back and leg pain: mechanism of action and efficacy. Cleve Clin J Med 71:961-970, 2004

23. Nanjayan SK, Swamy GN, Yallappa S, Bommireddy R: Arachnoiditis following caudal epidural injections for the lumbo-sacral radicular pain. Asian Spine J 7:355-358, 2013

24. Noh SH, Heo DH: Whole cerebrospinal axis infection after lumbar epidural injection: a case report. Eur Spine J 24 (Suppl 4):S525-S528, 2015

25. Plastaras C, McCormick ZL, Garvan C, Macron D, Joshi A, 
Chimes G, et al: Adverse events associated with fluoroscopically guided lumbosacral transforaminal epidural steroid injections. Spine J 15:2157-2165, 2015

26. Rosas HG, Lee KS: Performing fluoroscopically guided interlaminar lumbar epidural injections. AJR Am J Roentgenol 199:419, 2012

27. Saigal G, Donovan Post MJ, Kozic D: Thoracic intradural Aspergillus abscess formation following epidural steroid injection. AJNR Am J Neuroradiol 25:642-644, 2004

28. Shamliyan TA, Staal JB, Goldmann D, Sands-Lincoln M: Epidural steroid injections for radicular lumbosacral pain: a systematic review. Phys Med Rehabil Clin N Am 25:471489, 489.e1-489.e50, 2014

29. Staal JB, de Bie RA, de Vet HC, Hildebrandt J, Nelemans P: Injection therapy for subacute and chronic low back pain: an updated Cochrane review. Spine (Phila Pa 1976) 34:49-59, 2009

30. Wang YF, Fuh JL, Lirng JF, Chen SP, Hseu SS, Wu JC, et al: Cerebrospinal fluid leakage and headache after lumbar puncture: a prospective non-invasive imaging study. Brain 138:1492-1498, 2015

31. Werner BC, Cancienne JM, Browne JA: The timing of total hip arthroplasty after intraarticular hip injection affects postoperative infection risk. J Arthroplasty 31:820-823, 2016

32. Werner BC, Cancienne JM, Burrus MT, Griffin JW, Gwathmey FW, Brockmeier SF: The timing of elective shoulder surgery after shoulder injection affects postoperative infection risk in Medicare patients. J Shoulder Elbow Surg 25:390-397, 2016

33. Werner BC, Cancienne JM, Burrus MT, Park JS, Perumal V, Cooper MT: Risk of infection after intra-articular steroid injection at the time of ankle arthroscopy in a Medicare population. Arthroscopy 32:350-354, 2016

34. Yang S, Werner BC, Cancienne JM, Hassanzadeh H, Shimer $\mathrm{AL}$, Shen FH, et al: Preoperative epidural injections are associated with increased risk of infection after single-level lumbar decompression. Spine J 16:191-196, 2016

35. Yue WM, Tan SB: Distant skip level discitis and vertebral osteomyelitis after caudal epidural injection: a case report of a rare complication of epidural injections. Spine (Phila Pa 1976) 28:E209-E211, 2003

36. Zusman N, Munch JL, Ching A, Hart R, Yoo J: Preoperative epidural spinal injections increase the risk of surgical wound complications but do not affect overall complication risk or patient-perceived outcomes. J Neurosurg Spine 23:652655,2015

\section{Disclosures}

The authors report the following. Dr. Shimer is a consultant for NuVasive and serves on the speaker board for Stryker. Dr. Hassanzadeh is a consultant for NuVasive and receives support for non-study-related clinical or research efforts from Orthofix and Pfizer. Dr. Shen is a consultant for DePuy Synthes, Medtronic, and Globus.

\section{Author Contributions}

Conception and design: Singla, Yang, Shimer, Hassanzadeh, Shen. Acquisition of data: Yang, Werner, Cancienne. Analysis and interpretation of data: Yang, Werner, Cancienne. Drafting the article: Singla. Critically revising the article: Singla, Nourbakhsh. Reviewed submitted version of manuscript: Singla. Approved the final version of the manuscript on behalf of all authors: Singla. Statistical analysis: Werner. Study supervision: Singla, Shen.

\section{Supplemental Information}

\section{Previous Presentations}

The current study was previously presented at the 22nd International Meeting for Advanced Spinal Technologies (IMAST), July 8-11, 2015, Kuala Lumpur, Indonesia; the North American Spine Society (NASS) 30th Annual Meeting, October 14-17, 2015, Chicago, Illinois; and the American Association of Orthopaedic Surgeons (AAOS) 2016 Annual Meeting, March 1-5, 2016, Orlando, Florida.

\section{Current Affiliations}

Dr. Yang: Department of Orthopaedic Surgery, Oregon Health \& Science University, Portland, OR.

\section{Correspondence}

Anuj Singla, Department of Orthopaedic Surgery, University of Virginia Health System, 400 Ray C. Hunt Dr., Charlottesville, VA 22903. email: anujrajsingla@gmail.com. 